\title{
¿Privacidad y protección de datos de los animales? un debate necesario en tiempos de la pandemia de COVID-19
}

\author{
Josep Cañabate \\ Profesor de Historia del Derecho y las Instituciones \\ y en Sistemas Jurídicos Contemporáneos, Universitat Autònoma de Barcelona
}

Cita recomendada. CAÑABATE, J., ¿Privacidad y protección de datos de los animales? un debate necesario en tiempos de la pandemia de COVID-19, dA. Derecho Animal (Forum of Animal Law Studies) 11/4 (2020). - DOI https://doi.org/10.5565/rev/da.545

\section{Resumen}

En el contexto de la actual pandemia de COVID-19 el presente artículo tiene como objetivo principal poner de manifiesto la necesidad de garantizar un uso legítimo de la "información animal". Los avances en tecnologías de la información suponen unos riesgos y amenazas para los derechos de los animales. En consecuencia, se hace necesario abrir una reflexión sobre el método más idóneo para protegerlos. En primer lugar, se analiza el tratamiento de los datos animales desde la perspectiva de la normativa de protección de datos. Finalmente, se estudia la posibilidad de proteger la información de los animales.

Palabras clave: Protección de datos y animales; privacidad y animales; COVID-19 y animales.

Abstract - Privacy and the data protection of animals? A necessary debate in times of the COVID-19 pandemic

In the context of the current COVID-19 pandemic, the main objective of this article is to bring to light the need to guarantee legitimate use of "animal information". Advances in information technologies pose risks and threats to animal rights. Consequently, it is necessary to reflect on the most suitable method to protect them. Firstly, it analyses the treatment of animal data from the perspective of data protection regulations. Ultimately, it examines the possibility of protecting animal data.

Keywords: Data protection and animals; privacy and animals; COVID-19 and animals. 


\section{Introducción}

En el prefacio de Las palabras y las cosas: una arqueología de las ciencias humanas, Michel Foucault, uno de los filósofos más influyentes de la segunda mitad del siglo XX, daba cuenta al lector de un texto de Borges que iba a provocar una "larga vacilación e inquietud en nuestra práctica milenaria de lo Mismo y lo Otro". Este texto, según el pensador francés, citaba una "cierta enciclopedia china" donde estaba escrito "que 'los animales se dividen en a] pertenecientes al Emperador, b] embalsamados, c] amaestrados, d] lechones, e] sirenas, f] fabulosos, g] perros sueltos, $\mathrm{h}$ ] incluidos en esta clasificación, i] que se agitan como locos, j] innumerables, $\mathrm{k}$ ] dibujados con un pincel finísimo de pelo de camello, 1] etcétera, $\mathrm{m}$ ] que acaban de romper el jarrón, n] que de lejos parecen moscas". A través de esta "asombrosa taxonomía", iniciaba la mencionada obra en la que Foucault quería romper con los esquemas culturales, los estereotipos y lugares comunes que conducen a un pensamiento absolutamente desviado y eurocéntrico del otro.

El misterioso origen zoonótico de la pandemia de COVID-19 en China nos conduce a pangolines, murciélagos, y mercados húmedos donde se trafica con todo tipo de animales para consumo humano. Este escenario causa a Occidente el mismo asombro y desasosiego que la enciclopedia que imaginó el genial literato argentino. La mirada sobre el lejano Oriente sigue atrapada en esa distancia étnica y cultural sobre la que tan profusamente teorizó el pensador francés.

El filósofo y ensayista surcoreano Byung-Chul $\operatorname{Han}^{1}$ ha desentrañado algunas claves de la actual pandemia. Han, un oriental en Occidente, como el mismo se describe, nos sitúa ante la siguiente paradoja: la China con esa concepción y trato de los animales que nos causa perplejidad y rechazo, es la misma que ha conseguido doblegar la transmisión del virus a través de unas medidas muy restrictivas y de una vigilancia y control digital masivo e intensivo.

"La covid-19 probablemente no sea un buen presagio para Europa y Estados Unidos. El virus es una prueba para el sistema. Los países asiáticos, que creen poco en el liberalismo, han asumido con bastante rapidez el control de la pandemia, especialmente en el aspecto de la vigilancia digital y biopolítica, inimaginables para Occidente. Europa y Estados Unidos están tropezando. Ante la pandemia, están perdiendo su brillo. Zizek ha afirmado que el virus derribará el régimen de China. Zizek está equivocado. Eso no va a pasar. El virus no detiene el avance de China. China venderá su estado de vigilancia autocrática como modelo de éxito contra la epidemia. Exhibirá por todo el mundo aún con más orgullo la superioridad de su sistema. La covid-19 hará que el poder mundial se desplace un poco más hacia Asia. Visto así, el virus marca un cambio de era." 2

El control y la vigilancia digital "biopolítica" se erigen como modelos exitosos contra la lucha de la pandemia. Desde una Europa fracasada y devastada por los efectos sanitarios, sociales y económicos de la misma, se mira nuevamente con desconcierto al indescifrable gigante asiático. Ante la falta de una respuesta, ¿será la deriva autoritaria la solución?

El paradigma de privacidad europeo materializado en el Reglamento Europeo de Protección de Datos $(\mathrm{RGPD})^{3}$ se había erigido como paladín y baluarte en todo el mundo de los derechos y libertades de los ciudadanos europeos ${ }^{4}$. Especialmente contra los abusos y escándalos de los grandes proveedores de Internet, muchos de ellos ubicados en Estados Unidos, que habían salido a luz a través de casos como el del ex analista de la NSA, Edward Snowden, el Cambridge Analytica y las elecciones presidenciales estadounidenses de 2016, la Agencia de Inteligencia Rusa (IRA) y sus Fake News en Facebook, etc. Sin embargo, como señala el propio Han, la "virología" se superpone a la privacidad, y ya no solo interesan nuestras comunicaciones o nuestras opiniones en redes sociales. El objetivo es el control y disciplina de nuestro cuerpo, nuestro estado de salud, lo cual puede provocar una limitación de esos derechos y libertades, un abandono de la concepción

\footnotetext{
${ }^{1}$ Actualmente profesor en la Universidad de las Artes de Berlín y un referente intelectual europeo.

2 HAN, B-C. El virus es un espejo, muestra en qué sociedad vivimos. El Tiempo, 16/05/2020. Consultado el 9 de julio de 2020 desde https://www.eltiempo.com/mundo/asia/byung-chul-han-habla-del-efecto-del-coronavirus-en-las-personas-y-sociedades-496296.

${ }^{3}$ REGLAMENTO (UE) 2016/679 DEL PARLAMENTO EUROPEO Y DEL CONSEJO de 27 de abril de 2016 relativo a la protección de las personas físicas en lo que respecta al tratamiento de datos personales y a la libre circulación de estos datos y por el que se deroga la Directiva 95/46/CE (Reglamento general de protección de datos).

${ }^{4}$ Véase BESTARD PERELLO, J.J-. La pandemia del COVID19 y el tratamiento de datos personales (I). Actualidad del derecho sanitario, 282 (2020) 845-849. MARTÍNEZ, R. Los tratamientos de datos personales en la crisis del COVID-19. Un enfoque desde la salud pública. Diario La Ley, 9.604 (30 de marzo 2020). Wolters Kluwer. Consultado el 15 de noviembre de 2020 desde $\mathrm{https://diariolaley.laleynext.es/Content/Documento.aspx?params=H4sIAAAAAAAEAMtMSbF1CTEAAmMDc2NjM7Wy1KLizP}$ w8WyMDI6CYoSVIIDOt0iU_OaSyINU2LTGnOBUAZxgvATUAAAA=WKE.
} 
liberal postrevolucionaria 5 .

En consecuencia, ya se puede problematizar claramente, es el mencionado control y disciplina biopolítica de nuestro cuerpo lo que supone una mayúscula amenaza para nuestros derechos y libertades. En Europa será la normativa de privacidad la que tendrá que ponderar y hacer un balance entre el interés público y los derechos de los ciudadanos. Se deberá encontrar un equilibrio entre el loable objetivo de salvar vidas humanas y el mantenimiento de los mimbres democráticos de nuestra sociedad.

Aunque el control y la vigilancia biopolítica no se limita a los seres humanos, los animales de todo tipo y especie en determinadas circunstancias pueden ser objeto de un masivo e intenso seguimiento digital. Las finalidades y motivaciones de esta monitorización a través de sistemas de información pueden ser muy diversas: a) agropecuarias y ganaderas, b) veterinarias y fitosanitarias, c) científicas, d) estadísticas, e) control de plagas, f) seguimiento de animales en peligro de extinción, y el que nos ocupa g) control epidémico o pandémico.

Cada día en todo el mundo se tratan miles de millones de datos relacionados con animales para estos fines. Esta cantidad ingente de información es procesada a través de técnicas analíticas de Big Data, modelos basados en Inteligencia Artificial y algoritmos complejos, así como ficheros y bases de datos ${ }^{6}$. El tratamiento masivo y a gran escala de estos datos puede ser muy beneficioso para las finalidades señaladas, algunas de las cuales son de interés general o redundan directamente en los propios animales. No obstante, esos mismos tratamientos pueden ocultar decisiones puramente empresariales o comerciales, motivaciones espurias, algunas de las cuales ayudarán a legitimar de un modo "supuestamente científico y objetivo" decisiones que afecten y tengan un elevado impacto en el bienestar de los animales. La virología puede determinar que una determinada especie es un vector de contagio o que en una explotación ganadera concreta hay un elevado riesgo de transmisión. Las decisiones sanitarias apoyadas en datos pueden conducir al sacrificio de cientos o miles de animales ${ }^{7}$.

El núcleo de la cuestión se vislumbra con nitidez: el tratamiento de datos de animales se lleva a cabo sin control ni garantías, sin ponderación ni proporcionalidad. No existe un equivalente al derecho a la protección datos personales con el que cuentan los humanos. Por el contrario, la información animal puede ser tratada salvajemente sin ningún tipo de limitación, con opacidad absoluta, y eso puede tener un impacto fatal en los animales. En este sentido trabajos como el de Ewa Haratym "Animals right to privacy" 8 abogan por la existencia de un derecho que sería equivalente a la intimidad, es decir, a no ser perturbado.

Este estudio quiere reivindicar y poner de manifiesto la importancia de los datos y de la información animal como un componente esencial del bienestar animal y de sus derechos en el contexto de una sociedad que avanza a marchas aceleradas hacia su completa transformación digital. En este sentido, observamos como junto al animal real, en "carne y hueso" diríamos, hay una información digital sobre él, una suerte de identidad digital animal, que lo representa en los mencionados sistemas de información. Para proteger al animal real, hay que proteger su información digital. Por ese motivo abogamos por una privacidad y protección de datos de la información animal, como un nuevo derecho de los animales en la era digital. Cuando todavía se están asentando los derechos, que haciendo un paralelismo con los humanos, pudieran denominarse de primera generación, debemos plantearnos aquellos de tercera, los de garantía de los derechos digitales.

Una vez habiéndonos posicionado por la configuración de este derecho, podemos tratar de encontrar las aristas de nuestro ordenamiento jurídico que conduzcan a esa mayor protección. En este sentido se puede hablar de los animales como "datos personales" que identifican a una persona. Este supuesto se refiere a la información sobre animales domésticos o sobre animales de granja que puede identificar a una persona física. Desde la óptica de la protección de datos personales la reivindicación se dirigía a postular por la inclusión de la información sobre animales domésticos dentro de la categoría de datos especialmente protegidos. Esta categoría contempla los datos relacionados con la salud, la ideología, la orientación sexual, etc. Los datos de un perro, por ejemplo, en un fichero de una clínica veterinaria que pueden identifica a su dueño, serían considerados como ordinarios, al mismo nivel que los datos de un coche que puede tener un taller mecánico.

\footnotetext{
5 HAN, B-C. op. cit.

${ }^{6}$ Sobre el uso de inteligencia artificial y algoritmos por las autoridades públicas véase a BOIX, A. Los algoritmos son reglamentos: la necesidad de extender las garantías propias de las normas reglamentarias a los programas empleados por la administración para la adopción de decisiones. Revista de Derecho Público: Teoría y Método, 1 (2020) 223-270. Consultado el 1 de octubre de 2020 desde https://doi.org/10.37417/RPD/vol_1_2020_33; COTINO HUESO, L. Inteligencia artificial, big data y aplicaciones contra la COVID19: privacidad y protección de datos. Revista de Internent, Derecho y Política (2020) 1-17 y AEPD (2020). Adecuación al RGPD de tratamientos que incorporan Inteligencia Artificial (2020). Consultado el 5 de mayo de 2020 desde https://www.aepd.es/media/guias/adecuacion-rgpd-ia.pdf-.

${ }^{7}$ Estas acciones generan el rechazo de las entidades en defensa de los animales, pero ante la ciencia del dato están desarmados para concienciar a la sociedad de un posible abuso o desviación.

${ }^{8}$ HARATYM, E. Animals right to privacy. Worl Scientific New, 85 (2017) 73-77. Consultado el 1 de junio de 2020 desde http://www.worldscientificnews.com/wp-content/uploads/2017/08/WSN-85-2017-73-77-1.pdf.
}

56 Derecho Animal. Forum of Animal Law Studies, vol. 11/4 
Esta equiparación resulta a todas luces despreciable pero lamentablemente no dista mucho del tratamiento que le otorga nuestro ordenamiento.

Para desarrollar las cuestiones señaladas, además de esta introducción/problematización, este artículo se estructura en dos apartados: el primero sobre la consideración de la información animal como datos personales a la luz de la normativa; el segundo sobre un posible enfoque, sin más pretensiones que animar el debate académico y social, sobre un posible régimen de privacidad y protección de los datos animales

\section{Los animales como "dato personal".}

El artículo 4 apartado primero del RGPD establece la definición del concepto sustancial sobre el que se construye su régimen jurídico, el de dato personal. Esta norma define a este como "toda información sobre una persona física identificada o identificable («el interesado»); se considerará persona física identificable toda persona cuya identidad pueda determinarse, directa o indirectamente, en particular mediante un identificador, como por ejemplo un nombre, un número de identificación, datos de localización, un identificador en línea o uno o varios elementos propios de la identidad física, fisiológica, genética, psíquica, económica, cultural o social de dicha persona".

El concepto de dato personal, por tanto, es muy amplio e incluye una cantidad ingente de datos que o bien identifican directamente a la persona, como podrían ser su nombre, apellidos, dirección, etc., o bien la hacen identificable a través de medios técnicos. En esta última categoría es donde hallaríamos el exponencial crecimiento datos personales que están comportando el desarrollo de las tecnologías de la información. La geolocalización, los logs (registros) de nuestros mensajes a través de los servidores y nodos de comunicación, las "cookies" que registran nuestros hábitos de navegación en una web, etc. En consecuencia, la información personal se ha multiplicado creando elevados riesgos y amenazas para los usuarios.

La definición de datos personales se aplica a la identificación de personas físicas, excluyéndose del mismo a las personas jurídicas o a cualquier tipo de entidad o corporación de naturaleza análoga. La protección de datos personales, tal como determinó la Sentencia del Tribunal Constitucional 292/2000, de 30 de noviembre ${ }^{9}$, es un derecho fundamental y como tal solo puede aplicarse subjetivamente a las personas físicas.

Los animales en ningún caso son considerados sujetos de este derecho a la protección de datos personales. En consecuencia, per se no se les puede aplicar la protección dimanada de la normativa de privacidad. No obstante, en determinados supuestos los "datos animales" pueden servir para identificar o hacer identificable a una persona ${ }^{10}$. En este sentido, nos hallamos ante diversas casuísticas que van desde el tratamiento de datos de contactos básicos para facturación de los servicios veterinarios al propietario del anima $1^{11}$ a los sistemas de identificación y registro de animales de compañía.

Con relación a estos sistemas, como señala Giménez-Candela, están implementados o van a serlo en la mayoría de los Estados miembros de la UE. En España la competencia recae sobre las comunidades autónomas, lo cual ha generado la existencia de 17 registros de identificación de animales que, lamentablemente, no son interoperables ${ }^{12}$. La finalidad de los mismos es evitar las graves problemáticas asociadas con el abandono de perros y gatos, y con el tráfico ilegal de cachorros.

Este tipo de sistemas de registro e identificación, como destaca Giménez-Candela con una visión premonitoria, pueden ser muy útiles con finalidades de salud y sanitarias para evitar la propagación de enfermedades de origen animal:

"En este sentido una de las campañas recientes de la UE, ha puesto el acento en la necesidad de proveer de un pasaporte reglado a los animales de compañía en tránsito por Europa (Pet Travel Scheme), como medio de evitar la propagación de enfermedades (zoonosis) transmitidas por los animales. Es claro que el trasfondo de la campaña es alertar sobre la salud pública, pero, cada vez más se habla de "One Health", para hacer referencia no sólo a la salud humana sino también a la de los animales. Un control estricto de la identidad, procedencia, vacunaciones y pertenencia de los animales que circulan por territorio de la UE, sería uno de los elementos disuasorios más eficaces para combatir conductas claramente punibles, como lo es también el abandono, que en la reciente reforma del C.Penal español

\footnotetext{
${ }^{9}$ STC 292/2000, de 30 de noviembre,

http:/hj.tribunalconstitucional.es/es-ES/Resolucion/Show/4276\#complete resolucion\&fundamentos

${ }^{10}$ Agencia Española de Protección de Datos. Asunto "PEQUEÑOS ANIMĀLES SERVICIOS ESPECIALIZADOS SRL." Expediente $\mathrm{N}^{\circ}: \mathrm{E} / 00260 / 2018$.

11 Agencia Española de Protección de Datos. Asunto Registro Andaluz de Identificación Animal (RAIA). Expediente No: E/02203/2018 https://www.aepd.es/es/documento/e-00260-2018.pdf

${ }^{12}$ GIMÉNEZ-CANDELA, T. Animales de compañía en la UE: identificación y registro. dA. Derecho Animal (Forum of Animal Law Studies) 7/1 (2016) 1.
} 


\section{ha pasado a convertirse de falta en delito."13}

Estos métodos de identificación y registro fueron introducidos en España por la Ley 8/2003, de 24 de abril, de sanidad animal ${ }^{14}$. Su artículo 39 definió el Sistema Nacional de Identificación animal especificando que la Administración General del Estado es la responsable de establecer las bases y coordinación de un único y homogéneo sistema nacional de identificación de las diferentes especies animales.

Los animales deben identificarse de acuerdo con lo dispuesto al efecto en la normativa comunitaria europea o con el sistema establecido reglamentariamente por el Gobierno ${ }^{15}$. La obligación de identificarse corresponde a los titulares de las explotaciones ganaderas a las que pertenezcan los animales o a los propietarios o responsables de los animales según establecen el Real Decreto 479/2004, de 26 de marzo y el Real Decreto 728/2007, de 13 de junio ${ }^{16}$.

Estos sistemas de identificación, que han puesto en marcha, como se ha indicado las comunidades autónomas funcionan a través de páginas webs de acceso público en las cuáles se introduce un código numérico correspondiente al microchip del animal de compañía. Una vez realizada la mencionada operación se ofrece la siguiente información: los datos físicos del animal, nombre de pila de la persona propietaria, su número de teléfono, el municipio en el que está censando el animal y el teléfono del Ayuntamiento. Esta información atendiendo a la definición del mencionado artículo 4.1 del RGPD convierte a la "información sobre el animal" contenida en este dispositivo electrónico en dato personal, puesto que justamente su objetivo es lograr identificar al propietario del animal. Cabe señalar que cualquier persona que cuente con un lector de microchips, aparato que se puede comprar fácilmente en Internet por alrededor de 30 euros, podrá acceder a esos datos personales.

La base de legitimación para acceder a esta información seria la de una habilitación legal (art. 39 de la Ley 8/2003). Esta norma establece el sistema nacional de identificación, haciendo una remisión a la normativa europea, así como al sistema establecido reglamentariamente por el gobierno. El mencionado sistema proporciona el amparo legal exigido por el artículo 6 apartado d) del RGPD y artículo 8 de la Ley Orgánica de Protección de Datos Personales y Garantía de Derechos Digitales (en adelante LOPDGDD) ${ }^{17}$. No obstante, tal como señala la Agencia Vasca de Protección de Datos con relación a su sistema autonómico, al no hallarse recogido expresamente la identificación a través del microchip sería preferible acudir a otra base de legitimación para el tratamiento, como es la del interés legítimo. Para la aplicación de esta base de legitimación recogida en el artículo 6 letra f) del RGPD se deberían aplicar los principios de proporcionalidad, necesidad e idoneidad, y no utilizar la información personal obtenida con otra finalidad que no sea la de localizar al propietario del animal extraviado o abandonado.

Las clínicas veterinarias son responsables del tratamiento de datos personales relacionados con animales. La información obtenida por los veterinarios en el ejercicio de su actividad profesional está sometida al Código deontológico del ejercicio de la profesión veteranía ${ }^{18}$, aprobado por la asamblea general de presidentes de colegios del Consejo General de Colegios Veterinarios de 15 de diciembre de 2018. Esta normal

\footnotetext{
${ }^{13}$ GIMÉNEZ-CANDELA, T., Animales de compañía en la UE..., op. cit., p. 2.

${ }^{14}$ Ley 8/2003, de 24 de abril, de sanidad animal. (BOE, núm. 99, 25-04-2003, pág. 1-44). Disponible en: https://www.boe.es/buscar/act.php?id=BOE-A-2003-8510 (Consultado 2 de octubre de 2020).

${ }^{15}$ Véase Real Decreto 728/2007, de 13 de junio, por el que se establece y regula el Registro general de movimientos de ganado y el Registro general de identificación individual de animales. (BOE, núm. 155, de 29 de junio de 2007, págs. 1-22). Disponible en: https://www.boe.es/buscar/pdf/2007/BOE-A-2007-12694-consolidado.pdf; Real Decreto 479/2004, de 26 de marzo, (BOE, núm. 89, de 13 de abril de 2004, páginas 14978 a 14983). Disponible en: https://www.boe.es/buscar/doc.php?id=BOE-A-2004-6426 (Consultado 27 de noviembre de 2020). El mismo establece y regula el Registro general de explotaciones ganaderas, posibilitarán la realización de una trazabilidad completa de los animales de interés ganadero y permitirá a los titulares de las explotaciones ganaderas cumplir las obligaciones, respecto a la trazabilidad de los animales destinados a la producción de alimentos, establecidas por el Reglamento (CE) N. . 178/2002, del Parlamento Europeo y del Consejo, de 28 de enero de 2002, por el que se establecen los principios y los requisitos generales de la legislación alimentaria, se crea la Autoridad Europea de Seguridad Alimentaria y se fijan procedimientos relativos a la seguridad alimentaria. Diario Oficial de las Comunidades Europeas, L 31/1, pág. 1-24. Disponible en: https://eur-lex.europa.eu/legal-content/ES/TXT/PDF/?uri=CELEX:32002R0178\&from=ES (Consultado 27 de noviembre de 2020). Decisión de la Comisión de 22 de diciembre de 1999 por la que se modifica la Decisión 93/623/CEE de la Comisión y se regula la identificación de los équidos de crianza y de renta. Diario Oficial de las Comunidades Europeas, L 23/72, pág. 1-4. Disponible en: https://eur-lex.europa.eu/legal-content/ES/TXT/PDF/?uri=CELEX:32000D0068(01)\&from=EN (Consultado 27 de noviembre de 2020).

${ }^{16}$ Véase esta normativa citada supra.

${ }^{17}$ Ley Orgánica 3/2018, de 5 de diciembre, de Protección de Datos Personales y garantía de los derechos digitales. BOE, núm. 294, de 6 de diciembre de 2018, páginas 119788 a 119857. Disponible en: https://www.boe.es/buscar/doc.php?id=BOE-A-2018-16673.
} (Consultado 27 de noviembre de 2020).

18 Código deontológico del ejercicio de la profesión veteranía http://www.colvet.es/sites/default/files/201812/CO $\%$ CC $\% 81$ DIGO $\% 20$ DEONTOLO $\% C C \% 81 G I C O \% 20$ PARA $\% 20$ EL $\% 20$ EJERCICIO $\% 20 D E \% 20 L A \% 20 P R O F E S I O \% C C \%$ 81N\%20VETERINARIA\%20\%28Aprobado\%20AGPtes.\%2015-12-2018\%29.pdf (Visitado 5 de octubre de 2020). 
corporativa estableció la obligación de proteger la intimidad del cliente frente a terceros en base al secreto profesional:

“Artículo 7 del Código deontológico. El secreto profesional.

1. El secreto veterinario es inherente al ejercicio de la profesión veterinaria y se establece como un derecho del cliente a salvaguardar su intimidad frente a terceros. El veterinario está obligado a guardar el secreto profesional.

2. La obligación del secreto profesional se extiende a cuantos asuntos conozca el veterinario por información directa del cliente o por haberlo conocido en el ejercicio de la profesión. El veterinario tiene el deber de exigir, asimismo, a sus colaboradores o empleados discreción y observación escrupulosa del secreto profesional que también les incumbe.

(...)

4. Cuando un veterinario cese en su trabajo privado, una copia de su archivo podrá ser transferido al veterinario que le suceda, siempre que los clientes manifiesten su consentimiento de forma expresa, y en todo caso con respeto y cumplimiento de la normativa vigente, especialmente la relativa a la protección de datos de carácter personal."

Por otra parte, el Código deontológico prevé la posibilidad de que los datos animales puedan ser utilizados en publicaciones divulgativas siempre que se respete la intimidad y la protección de datos personales.

"Artículo 39 del Código deontológico. Publicaciones divulgativas.

1. El análisis de los datos obtenidos en la actuación veterinaria puede proporcionar informaciones muy valiosas, por lo que su publicación es autorizable desde el punto de vista deontológico, siempre que se respete el derecho a la intimidad del cliente así como la normativa vigente en materia de protección de datos de carácter personal. Se prohíbe cualquier otra finalidad sin la autorización expresa del cliente.“

En el contexto de pandemia las investigaciones científicas que puedan surgir a partir de la información animal que tratan los veterinarios, u otros organismos pueden tener un valor crucial. En este sentido, debemos hacer referencia a las resoluciones y pronunciamientos aprobados por diversas instituciones europeas en el marco de la pandemia de COVID ${ }^{19}$. En primer lugar, se debe mencionar las Directrices 03/2020 ${ }^{20}$ del Comité Europeo de Protección de Datos (CEPD en adelante) sobre el procesamiento de datos relativos a la salud con fines de investigación científica en el contexto del brote de COVID-19, pese a no ser la primera vez que se pronuncia en lo relativo a investigaciones científicas y/o ensayos clínicos. Este documento se centra exclusivamente en las implicaciones que la situación actual de excepcionalidad puede suponer en estos ámbitos, así como en la necesidad de llevar a cabo investigaciones científicas que permitan, a la mayor brevedad posible, poder encontrar una solución que posibilite frenar el avance de la pandemia.

En el documento se introducen determinadas novedades que resulta preciso traer a colación. En primer lugar, en lo relativo a la legitimación del tratamiento de los datos personales, se abre la posibilidad de articular el consentimiento como una base jurídica habilitante, tanto en lo concerniente al artículo 6, como por lo que se refiere a su utilización como excepción a la prohibición general para el tratamiento de categorías especiales de datos personales recogida en el artículo 9 del Reglamento General de Protección de Datos.

\footnotetext{
${ }^{19}$ CEPD. Statement of the EDPB Chair on the processing of personal data in the context of the COVID-19 outbreak. (20 de marzo 2020). Consultado el 5 de mayo de 2020 desde https://edpb.europa.eu/news/news/2020/statement-edpbchair-processing-personaldata-context-Covid-19-outbreak_en. En Reino Unido véase Information Commissioner's Office (en adelante, ICO). Data protection and coronavirus. (12 de marzo 2020). https://ico.org.uk/about-the-ico/newsand-events/news-and-blogs/2020/03/data-protection-andcoronavirus. Véase igualmente el Informe de la Agencia Española de Protección de Datos (en adelante AEPD). Informe 175/2018, noviembre, sobre investigación biomédica (2020). AEPD. Adecuación al RGPD de tratamientos que incorporan Inteligencia Artificial (2020). Consultado el 5 de mayo de 2020 desde https://www.aepd.es/media/guias/adecuacion-rgpd-ia.pdf-. AEPD. Informe 20/2020, de 12 de marzo, en relación con los tratamientos de datos resultantes de la actual situación derivada de la extensión del virus COVID19 (2020). Consultado el 5 de mayo de 2020 desde https://www.aepd.es/es/documento/2020-0017.pdf. AEPD. El uso de las tecnologías en la lucha contra el Covid19. Un análisis de costes y beneficios (Mayo de 2020). Consultado el 1 de junio de 2020 desde https://www.aepd.es/sites/default/files/2020-05/analisis-tecnologias-COVID19.pdf. APDCAT. Nota en relación a los tratamientos de datos personales relacionados con las medidaspara hacer frente al COVID-19 (15 de marzo 2020). Consultado el 5 de mayo de 2020 desde https://apdcat.gencat.cat/ca/actualitat/noticies/noticia/Nota-en-relacio-amb-els-tractaments-de-dades-personals-relacionatsamb-les-mesures-per-fer-front-al-COVID-19

${ }^{20}$ Véase CEPD, Directrices 03/2020 sobre el procesamiento de datos relativos a la salud con fines de investigación científica en el contexto del brote de COVID-19, a través del siguiente enlace (en inglés). Consultado el 14 de abril de 2020 desde https://edpb.europa.eu/our-work-tools/our-documents/guidelines/guidelines-032020-processing-data-concerning-health-purpose_en
} 
El CEPD, sin embargo, es tradicionalmente reacio a la posibilidad de admitir la utilización del consentimiento como base de legitimación suficiente para habilitar un tratamiento de datos personales máxime cuando se trata de categorías especiales de datos personales-, debido a que resulta complicado demostrar en la mayoría de las ocasiones que el mismo ha sido emitido de conformidad con las exigencias que establece al respecto la legislación aplicable en materia de protección de datos. Entre otras consideraciones este consentimiento debe constituirse como una manifestación de voluntad libre, específica, informada e inequívoca del interesado.

Por este mismo motivo, es preciso recordar que para el tratamiento de categorías especiales no es suficiente con contar únicamente con alguna de las bases legitimadoras que aparecen expresamente recogidas en el art. 6 del RGPD, sino que además deberá concurrir una de las circunstancias previstas en el art. 9 RGPD, esto es, alguna excepción a la regla general que imposibilita el tratamiento de categorías especiales de datos personales.

En cualquier caso, resulta necesario traer a colación las disposiciones establecidas por el RGPD al respecto a través de su Considerando $\mathrm{n}^{\circ} 43$, cuyo tenor literal reza:

"Para garantizar que el consentimiento se haya dado libremente, este no debe constituir un fundamento jurídico válido para el tratamiento de datos de carácter personal en un caso concreto en el que exista un desequilibro claro entre el interesado y el responsable del tratamiento, en particular cuando dicho responsable sea una autoridad pública y sea por lo tanto improbable que el consentimiento se haya dado libremente en todas las circunstancias de dicha situación particular. Se presume que el consentimiento no se ha dado libremente cuando no permita autorizar por separado las distintas operaciones de tratamiento de datos personales pese a ser adecuado en el caso concreto, o cuando el cumplimiento de un contrato, incluida la prestación de un servicio, sea dependiente del consentimiento, aun cuando este no sea necesario para dicho cumplimiento".

Adicionalmente, también se habilitan el interés legítimo y el interés público como posibles bases de legitimación para los tratamientos de datos personales que se pretendan efectuar en el marco de las investigaciones científicas, las cuáles, deberán de ser aplicadas conjuntamente con alguna de las excepciones preceptuadas por el artículo 9 del RGPD, concretamente se cita el interés público en el ámbito de la salud pública y los tratamientos llevados a cabo con fines de archivo en interés público, fines de investigación científica o histórica o fines estadísticos. Teniendo en cuenta, que, además, que ello deberá de complementarse con aquellas particularidades que puedan existir al respecto en el ordenamiento jurídico de cada Estado Miembro.

Por otra parte, conviene señalar que el régimen que se establece por las instituciones europeas si lo aplicamos a la información animal que se utilice con finalidades sanitarias va a proteger al propietario, nunca al animal. Por otra parte, se debe hacer otra importante consideración, y es que los datos de los animales no se comprenden dentro de las categorías especiales de datos personales, lo cual conlleva un régimen mucho menor de protección. La norma europea tipifica dentro de esta categoría especial los siguientes datos:

"Artículo 9 RGPD. Tratamiento de categorías especiales de datos personales

1.Quedan prohibidos el tratamiento de datos personales que revelen el origen étnico o racial, las opiniones políticas, las convicciones religiosas o filosóficas, o la afiliación sindical, y el tratamiento de datos genéticos, datos biométricos dirigidos a identificar de manera unívoca a una persona física, datos relativos a la salud o datos relativos a la vida sexual o las orientaciones sexuales de una persona física."

A esta prohibición genérica son aplicable excepciones, entre las cuales estaría el interés público en el ámbito de la salud pública:

“i) el tratamiento es necesario por razones de interés público en el ámbito de la salud pública, como la protección frente a amenazas transfronterizas graves para la salud, o para garantizar elevados niveles de calidad y de seguridad de la asistencia sanitaria y de los medicamentos o productos sanitarios, sobre la base del Derecho de la Unión o de los Estados miembros que establezca medidas adecuadas y específicas para proteger los derechos y libertades del interesado, en particular el secreto profesional."

Esta previsión debe interpretarse a la luz de la explicación que realiza el Considerando 46 del RGPD:

Considerando 46 RGPD. (...) "Ciertos tipos de tratamiento pueden responder tanto a motivos importantes de interés público como a los intereses vitales del interesado, como por ejemplo cuando el 
tratamiento es necesario para fines humanitarios, incluido el control de epidemias y su propagación, o en situaciones de emergencia humanitaria, sobre todo en caso de catástrofes naturales o de origen humano."

Como vemos la situación actual permite por razones de interés público el tratamiento de los datos de salud, que tal como se ha dicho están considerados categorías especiales. No obstante, la normativa actual no contempla o excluye a los "datos de los animales de compañía" de ese nivel superior de protección. No existe ningún pronunciamiento institucional a favor de su inclusión, pero hay razones fundamentadas para entender que los datos de los animales de compañía deberían gozar de este estatus de superior protección. En concreto, se podría englobar dentro de los hábitos de vida de una persona, y por tanto bajo la rúbrica de datos de salud. Los animales de compañía cuentan con una relación afectiva, emocional y psicológica con el propietario en la mayoría de casos de tal intensidad y profundidad que debería considerarse dentro de un concepto amplio de salud y de hábitos de vida.

La inclusión en la categoría especial de la información otorgaría de manera indirecta una protección suplementaria que podría evitar los usos abusivos o malintencionados que puede comprometer seriamente el bienestar animal.

Una vez analizado la aproximación a través del marco legal existente, en el siguiente apartado para finalizar este estudio, se va a realizar a modo propositivo una reflexión sobre la posibilidad de que los animales tengan derecho a la protección de datos de modo análogo a las personas humanas.

\section{3. ¿Tienen los animales derecho a la privacidad y a la protección de datos?}

Las epidemias de origen zoonótico conllevan en muchas ocasiones decisiones, supuestamente avaladas por la ciencia, que pueden llevar incluso el sacrificio de miles de animales. La pandemia de COVID no es una excepción en este sentido, a modo de ejemplo, se puede mencionar como el gobierno de Dinamarca ha ordenado sacrificar a 17 millones de visones tras la detección de una nueva variante del coronavirus SARSCoV-2 que se expandido en los animales de granja y ha pasado a humanos ${ }^{21}$. En los Países Bajos hace unos meses sucedió un supuesto similar, y en España se sacrificaron en una granja de La Puebla de Valverde, Teruel, a casi 100.000 ejemplares.

Las mutaciones del virus ciertamente son muy peligrosas, y podrían comportar de facto una nueva pandemia ante la cual las vacunas que están en fase final no tengan efecto. Sin discutir que la medida sea necesaria por motivos sanitarios, el sacrificio de millones de animales sin duda debería realizarse con exquisito test de ponderación, que atendiese a la necesidad y a la idoneidad de las medidas que conducen a poner fin a la vida de estos seres vivos. Los equilibrios no son fáciles en contextos como el actual, por este motivo se hace necesario una política de "datos abiertos", que de manera transparente aporte los elementos necesarios para que toda la comunidad científica, así como aquellas entidades protectoras de los animales puedan realizar la imprescindible y necesaria función de revisión y control de los resultados.

Sin embargo, toda aquella información animal que no identifique a una persona está total y absolutamente desprotegida. Cualquier institución puede tratar la información animal sin ningún tipo de garantía, puede elaborar modelos a partir de inteligencia artificial sesgados que justifiquen la adopción de una determinada política, o pueden venderse con fines puramente comerciales. Como se argumentaba al inicio de este trabajo la "información digital de los animales" se convierte en elemento a garantizar y defender por el alto impacto que puede tener en su bienestar y en sus derechos. En este sentido, es cuando nos podemos plantear si debería existir un derecho a la protección de datos de los animales, sin distinción alguna, como un elemento necesario e imprescindible para garantizar los derechos animales en el contexto de gran avance tecnológico actual.

A buen seguro desde una perspectiva antropocéntrica esta afirmación podrá suponer una aberración jurídica, ¿los animales con derecho a la intimidad o a la protección de datos? Sin embargo, si abandonamos la subjetividad y nos fijamos en la necesidad de garantizar el uso legítimo de la información animal podemos abogar por la utilización de mecanismos de garantía propios del ámbito de la "privacidad humana".

En consecuencia, se podría proponer un marco de cumplimiento normativo para proteger estos datos,

\footnotetext{
${ }^{21}$ DOMÍNGUEZ, N., DOMÍNGUEZ CEBRIÁN, B. Dinamarca matará 17 millones de visones para frenar una nueva variante del coronavirus que ha saltado a humanos. El País, 6/11/2020. Consultado el 6 de noviembre de 2020 desde https://elpais.com/ciencia/2020-11-05/dinamarca-matara-12-millones-de-visones-para-frenar-una-nueva-variante-del-coronavirusque-ha-saltado-a-humanos.html
} 
el cual por analogía con el RGPD debería partir de los siguientes principios relativos al tratamiento de los datos de animales, los cuales se recogen en su artículo 6:

Los datos de los animales serán:

a) tratados de manera lícita, leal y transparente en relación con el interesado («licitud, lealtad y transparencia»);

b) recogidos con fines determinados, explícitos y legítimos, y no serán tratados ulteriormente de manera incompatible con dichos fines, el tratamiento ulterior de los datos personales con fines de archivo en interés público, fines de investigación científica e histórica o fines estadísticos no se considerará incompatible con los fines iniciales («limitación de la finalidad»);

c) adecuados, pertinentes y limitados a lo necesario en relación con los fines para los que son tratados («minimización de datos»);

d) exactos y, si fuera necesario, actualizados; se adoptarán todas las medidas razonables para que se supriman o rectifiquen sin dilación los datos personales que sean inexactos con respecto a los fines para los que se tratan («exactitud»);

e) mantenidos de forma que se permita la identificación de los afectados durante no más tiempo del necesario para los fines del tratamiento de los datos; la información de los animales podrán conservarse durante períodos más largos siempre que se traten exclusivamente con fines de archivo en interés público, fines de investigación científica o histórica o fines estadísticos, sin perjuicio de la aplicación de las medidas técnicas y organizativas apropiadas a fin de proteger los derechos («limitación del plazo de conservación»);

f) tratados de tal manera que se garantice una seguridad adecuada de los datos, incluida la protección contra el tratamiento no autorizado o ilícito y contra su pérdida, destrucción o daño accidental, mediante la aplicación de medidas técnicas u organizativas apropiadas («integridad y confidencialidad»).

El responsable del tratamiento será responsable del cumplimiento de lo dispuesto en el apartado 1 y capaz de demostrarlo («responsabilidad proactiva»).

La aplicación de estos principios resultaría el marco jurídico sustancial para garantizar esa información. Por otra parte, resultaría imprescindible delimitar los derechos conocidos como ARCO plus, estos son fundamentales para que se produzca el efectivo control de los datos animales. El ejercicio de esto derechos podría llevarse a cabo por organizaciones privadas o públicas que tengan como objeto social la defensa de los intereses de los animales. Los mismos se corresponderían con los derechos establecidos en los artículos 15 y siguientes del RGPD, es decir, derecho de acceso, derecho de rectificación, derecho de supresión, derecho de oposición, derecho de limitación del tratamiento.

A modo de ejemplo podemos mencionar como el derecho acceso podría ser fundamental para conocer aspectos tales como las finalidades del tratamiento, identificar responsables, conocer si se van a llevar a cabo decisiones automatizadas. Por otra parte, el derecho de acceso debería unirse a las obligaciones de transparencia de aquellas personas que utilicen animales en granjas, explotaciones, zoológicos, etc.

Como observamos un derecho animal a la protección de datos puede ser fundamental para garantizar el bienestar animal. Este análisis ha pretendido, como índica su título, abrir un debate sobre la necesidad de conceptualizar un derecho de nueva creación a la protección de datos de la información animal.

\section{Conclusiones}

La lucha contra la pandemia de COVID-19 ha legitimado la toma decisiones, sin el suficiente control y transparencia, que han afectado fatalmente a millones de animales. Este estudio ha puesto de manifiesto la necesidad de proteger a la información de los animales como un a priori imprescindible para garantizar el resto de derechos de sus derechos. El exponencial avance de las tecnologías de la información conlleva unos riesgos y amenazas en el tratamiento de la información animal a través del uso de la Inteligencia Artificial, del Big Data u otras tecnologías analísticas. Sin embargo, el ordenamiento jurídico actual a través del RGPD y la LOPDGDD solo protege la información animal en tanto que sea un "dato personal" que identifica a una persona humana. Este régimen además de ser totalmente insuficiente, solo protegería la información de animales de compañía, y en menor medida aquellos de explotaciones ganaderas.

Desde esta óptica el artículo llega a la conclusión de que los datos de los animales de compañía deberían comprenderse como aquellos relacionados con salud, lo cual comportaría un régimen jurídico de protección superior. Por otra parte, para superar las dificultades señaladas y otorgar a todos los animales un nivel adecuado de protección sería necesario elaborar un derecho a la protección de datos animales, el cual 
incorporase principios básicos de la normativa de protección de datos personales. El ejercicio de estos derechos debería recaer en organizaciones que tengan como finalidad la defensa del bienestar animal.

\section{Bibliografía}

- AEPD. Informe 175/2018, noviembre, sobre investigación biomédica (2018)

- AEPD. Adecuación al RGPD de tratamientos que incorporan Inteligencia Artificial (2020). Consultado el 5 de mayo de 2020 desde https://www.aepd.es/media/guias/adecuacion-rgpd-ia.pdf-.

- AEPD. Informe 20/2020, de 12 de marzo, en relación con los tratamientos de datos resultantes de la actual situación derivada de la extensión del virus COVID-19 (2020). Consultado el 5 de mayo de 2020 desde https://www.aepd.es/es/documento/2020-0017.pdf.

- AEPD. El uso de las tecnologías en la lucha contra el Covid19. Un análisis de costes y beneficios (Mayo de 2020). Consultado el 1 de junio de 2020 desde https://www.aepd.es/sites/default/files/2020-05/analisis-tecnologias-COVID19.pdf.

- APDCAT. Nota en relación a los tratamientos de datos personales relacionados con las medidas para hacer frente al COVID-19 (15 de marzo 2020). Consultado el 5 de mayo de 2020 desde https://apdcat.gencat.cat/es/actualitat/noticies/noticia/Nota-en-relacio-amb-els-tractaments-dedades-personals-relacionats-amb-les-mesuresper-fer-front-al-COVID-19.

- BOIX, A. Los algoritmos son reglamentos: la necesidad de extender las garantías propias de las normas reglamentarias a los programas empleados por la administración para la adopción de decisiones. Revista de Derecho Público: Teoría y Método, 1 (2020) 223-270. Consultado el 1 de octubre de 2020 desde https://doi.org/10.37417/RPD/vol_1_2020_33.

- COMISIÓN EUROPEA (2020b). Recomendación (UE) 2020/518 de la Comisión de 8 de abril de 2020. Consultado el 5 de mayo de 2020 desde https://eur-lex.europa.eu/legalcontent/ES/TXT/?uri=uriserv:OJ.L_.2020.114.01.0007.01.SPA\&toc=OJ:L:2020:114:TOC.

- BESTARD PERELLO, J.J-. La pandemia del COVID19 y el tratamiento de datos personales (I). Actualidad del derecho sanitario. 282 (2020) 845-849.

- COTINO HUESO, L. Inteligencia artificial, big data y aplicaciones contra la COVID-19: privacidad y protección de datos. Revista de Internet, Derecho y Política (2020) 1-17.

- CEPD. Statement of the EDPB Chair on the processing of personal data in the context of the COVID-19 outbreak. (20 de marzo 2020). Consultado el 5 de mayo de 2020 desde https://edpb.europa.eu/news/news/2020/statement-edpbchair-processing-personal-data-contextCovid-19-outbreak_en.

- CEPD. Directrices 03/2020 sobre el tratamiento de datos relativos a la salud con fines de investigación científica en el contexto del brote de COVID-19 (Abril 2020). Consultado el 5 de mayo de 2020 desde https://edpb.europa.eu/ourwork-tools/our-documents/guidelines/guidelines032020-processing-data-concerning-healthpurpose_es.

- GIMÉNEZ-CANDELA, T. Animales de compañía en la UE: identificacion y registro. dA. Derecho Animal (Forum of Animal Law Studies) 7/1 (2016) 1-3.

- HARATYM, E. Animals right to privacy. Worl Scientific New, 85 (2017) 73-77. Consultado el 1 de junio de 2020 desde http://www.worldscientificnews.com/wp-content/uploads/2017/08/WSN85-2017-73-77-1.pdf.

- ICO. Data protection and coronavirus. (12 de marzo 2020). https://ico.org.uk/about-theico/newsand-events/news-and-blogs/2020/03/data-protection-and-coronavirus.

- MARTÍNEZ, R. Los tratamientos de datos personales en la crisis del COVID-19. Un enfoque desde la salud pública. Diario La Ley, 9.604 (30 de marzo 2020). Wolters Kluwer. Consultado el 15 de noviembre de 2020 desde:

https://diariolaley.laleynext.es/Content/Documento.aspx?params=H4sIAAAAAAAEAMtMSbF1C TEAAmMDc2NjM7Wy1KLizPw8WyMDI6CYoSVIIDOt0iU_OaSyINU2LTGnOBUAZxgvATU $\mathrm{AAAA}=\mathrm{WKE}$. 